\title{
Seed Treatment: A Strong Crop Management Strategy during Covid-19 Pandemic
}

\section{Sangita Sahni*}

Department of Plant Pathology, TCA, Dholi, RPCAU, Pusa, Bihar, India

*Corresponding Author: Sangita Sahni, Department of Plant Pathology, TCA, Dholi, RPCAU, Pusa, Bihar, India.
Received: April 23, 2021

Published: May 26, 2021

(C) All rights are reserved by Sangita Sahni.
The on-going health crisis due to COVID19 pandemic has affected all walks of life including agriculture. The ongoing second wave of COVID19 has made the situation further miserable. Although a slogan "everything can wait except agriculture" is prevailing but the ongoing pandemic and lockdown has affected the agriculture to a large extent. A plethora of report indicates the interruption of agricultural activities due to non-availability of migrant labour, disruption in supply chain, financial crisis etc. The successful crop cultivation requires management of crop throughout the cropping season. Apart from sowing and harvesting of crop, several management practices are being carried out intermittently to keep the crop plant healthy. The rise of mechanization in agriculture has reduced the time and dependency of labour in sowing and harvesting of crop plants to a large extent. However, the management of diseases, insect pest, nutrient application, irrigation etc are still largely depending upon supply of labour and timely completion of these activities for sustainable production and productivity. As seed treatment is a well proven technology to protect seeds/planting materials not only from pathogens but also provide several beneficial effects to crop growth and development without any extra effort after planting. Different seed treatments are being used alone or in combination to prevent a number of insect/ pests, diseases, nutrient deficiencies, stress mitigation etc. The seed treatment includes the use of fungicides, insecticides, inoculants, biofertilizers, plant growth regulators, nano materials etc. Conventionally, seed treatments were used for protection of seed and seedlings against various disease and insect pressure from the moment they are planted. The recent advancement in seed treatment with different bioagents and nanomaterials has further revolutionized the process. Treatments with bioagents have shown improvement in seed germination, seedling vigour, availability of nutrients (like nitrogen, phosphate, potash etc.), reduction in the incidence of seed-borne pathogens etc. Seed priming with nano materials is a promising technique to improve seed germination, seedling growth, pest control, plant nutrition etc. more efficiently. The use of nano materials has also shown enhanced seed vigour and seedling growth under stress conditions like salt stress. In this difficult time, if farmer don't able to take proper and timely care of their crops or escape some or all management steps at different stage of crop growth period due to time or financial crisis then the seed treatment will be the perfect and profitable tool for farmers.

\section{Volume 5 Issue 6 June 2021}

(C) All rights are reserved by Sangita Sahni. 